\title{
CURRÍCULO INTEGRADO PARA A BIODIVERSIDADE DA AMAZÔNIA
}

\author{
Lucinaldo da Silva BLANDTT \\ Campus Universitário de Bragança/UFPA \\ lucinaldoblandtt@ufpa.br
}

Resumo: $O$ presente artigo é um exercício que busca incentivar a discussão do conceito cientifico e pedagógico de currículo integrado e sua relação com a identidade sociocultural e biológica da Amazônia, em praxe, a biodiversidade na visão antropológica; é evidente que essa discussão é muito ampla, e que aqui não se esgotará, apenas insistirá em diversas opiniões que, decerto, fortalecerão a importância das práticas pedagógicas do currículo integrado focado no local e suas caracterizações especiais. O Currículo Integrado faz parte de uma concepção de organização da aprendizagem que tem como finalidade oferecer uma educação que contemple todas as formas de conhecimento produzidas pela atividade humana. Trata-se de uma visão progressista de educação à medida que não separa o conhecimento acumulado pela humanidade na forma de conhecimento científico daquele adquirido pelos educandos no cotidiano das suas relações culturais e materiais. A relação dos conhecimentos de biodiversidade e educação precisa está aplicada no currículo integrado, resultando, assim, em práticas de educação ambiental interdisciplinares. Ao ser considerada a Educação Ambiental como um processo social indispensável à formação da mentalidade dos cidadãos de uma sociedade, passa-se à crença de que a escola é o espaço ideal para a socialização do conhecimento que é o resultado de um longo processo: a relação do homem com a natureza e com os outros homens.

Palavras-chaves: Currículo integrado. Biodiversidade. Educação ambiental. Interdisciplinaridade.

Abstract: This article is an exercise that seeks to encourage discussion of the scientific concept of integrated curriculum and teaching and its relationship with the biological and socio-cultural identity of the 


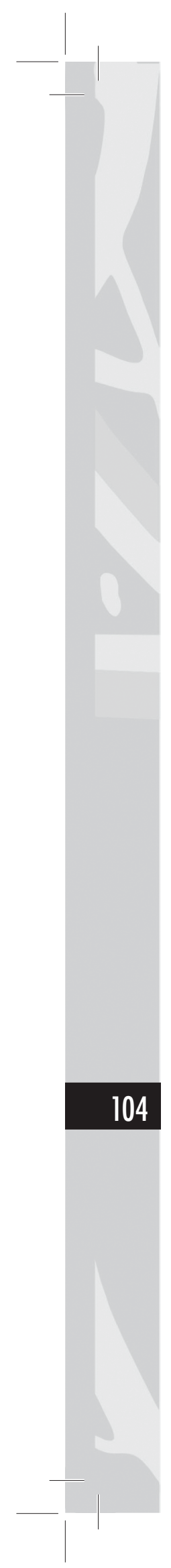

Amazon, in practice, the biodiversity in the anthropological view, it is clear that this discussion is very broad, and here do not exhaust, just insisted on several opinions that, right, strengthen the importance of the pedagogical practices of the integrated curriculum focused on the spot, and his characterizations special. The integrated curriculum is part of a concept of the learning organization that aims to provide an education that covers all forms of knowledge produced by human activity. It is a progressive vision of education as it does not separate the knowledge accumulated by humanity in the way that scientific knowledge acquired by students in their daily lives and cultural relations materials. The relation of knowledge of biodiversity and education needs is applied in the integrated curriculum, thus resulting in interdisciplinary environmental education practices. To be considered environmental education as a social process essential for the formation of the mentality of the citizens of a society, pass up the belief that the school is the ideal space for the socialization of knowledge that is the result of a long process: the relationship of man with nature and with others.

Keywords: Integrated curriculum. Biodiversity. Environmental education. Interdisciplinary.

\section{Introdução}

Nos últimos anos, em um mundo cada vez mais globalizado e interligado, a preocupação com um ensino mais integrado ganha destaque nos debates educacionais, orientando a construção e a concretização das propostas curriculares. Currículo é o objeto de estudo e análise deste trabalho, apresenta como eixo central a reorganização curricular baseada na integração, via interdisciplinaridade e contextualização junto aos conhecimentos socioambientais que fortalecem a identidade cultural da Amazônia. Por intermédio desses princípios formam um ensino polivalente e flexível e propõe um currículo dividido em áreas, abrangendo disciplinas entendidas como mais afins entre si.

Apesar de o discurso oficial orientar a nova organização curricular para o reconhecimento e a aceitação de que o conhecimento é uma construção coletiva (MEC/SEMTEC, 1999, vol. I, p. 75), a 
ideia de disciplina trabalhada nos documentos parece querer estar isenta das relações sociais, pois não há um questionamento quanto à sua forma de organização e seleção. Além disso, inúmeras vezes o conhecimento escolar não é tratado como se fosse o próprio conhecimento científico-tecnológico valorizado no mundo do trabalho, uma vez que o aprendizado deve possibilitar ao aluno a compreensão tanto dos processos químicos em si quanto da construção de um conhecimento científico em estreita relação com as aplicações tecnológicas (MEC/SEMTEC, 1999, vol. III, p. 31). Não é considerado que o conhecimento escolar não é igual ao conhecimento científico-tecnológico: existem processos de transposição didática e de recontextualização (Bernstein, 1996a), a fim de atender aos objetivos escolares e às relações sociais existentes no espaço escolar.

O presente artigo é um exercício que busca incentivar a discussão do conceito cientifico e pedagógico de currículo integrado e sua relação com a identidade sociocultural e biológica da Amazônia, em praxe, a biodiversidade na visão antropológica; é evidente que essa discussão é muito ampla, e que aqui não se esgotará, apenas insistirá em diversas opiniões que, decerto, fortalecerão a importância das práticas pedagógicas do currículo integrado focado no local, e suas caracterizações especiais.

\section{Currículo integrado}

O currículo tem significados que vão muito além daqueles aos quais as teorias tradicionais nos confinaram. $\mathrm{O}$ currículo é lugar, espaço, território. O currículo é relação de poder. O currículo é trajetória, viagem, percurso. O currículo é autobiografia, nossa vida, curriculum vitae: no currículo se forja nossa identidade. O currículo é texto, discurso, documento. $\mathrm{O}$ currículo é documento de identidade (SILVA, 2009, p. 150).

Tentar captar de uma forma abrangente todo o movimento que o currículo, entendido como proposta de organização escolar, fez desde que foi concebido como tal, é uma tarefa difícil, especialmente pela variedade de teorias e ou discursos sobre ele produzidos no último século, em especial na segunda 


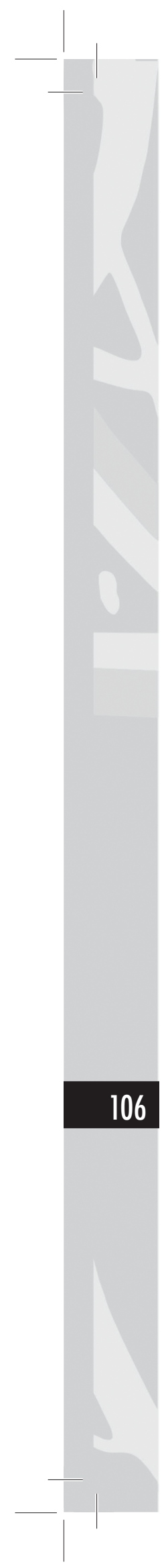

metade do século XX. Porém, há produções de fôlego para apoiar a elaboração deste trabalho em sua proposta: descrever e analisar um pouco do que já se disse sobre o tema, à luz das elaborações produzidas na esfera mais ampla do pensamento sobre a Educação, seu caráter na sociedade capitalista e seu papel nos processos de superação do capitalismo e proposição de uma sociedade mais justa e mais fraterna.

Pensar o currículo para alguns educadores remete a uma ideia de formulação e organização de listas de conteúdo a serem ministrados, com os devidos procedimentos metodológicos. Uma perspectiva crítica na Educação já não admite a neutralidade no processo de construção do currículo, e esse, é organizado com um viés político e epistemológico, como nos diz Moreira e Silva (2002): "O currículo é uma área contestada, é uma arena política" (p. 21).

Segundo Ciavatta (2005), o sonho de uma formação completa partiu dos primeiros socialistas que buscavam o viés "omnilateral no sentido de formar o ser humano na sua integralidade física, mental, cultural, política, científicotecnológica" (p. 86). O que caracteriza o currículo integrado é a junção da formação específica (técnica) com a formação geral: "Poderíamos tentar definir o currículo integrado como um plano pedagógico e sua correspondente organização institucional que articula dinamicamente trabalho e ensino, prática e teoria, ensino e comunidade" (DAVINI, 1999, p. 284).

Pensar o trabalho como atividade de produção, no sentido de produtivismo, é ir ao encontro da alienação humana. No conceito marxiano, o trabalho é realização, e a produção deve estar ligada à atividade criadora, e não meramente reprodutora. O trabalho é a expressão da práxis, na qual o homem se relaciona com a natureza, com os outros homens, transformando os outros e a si mesmo. Assim, o trabalho deve ser visto como um 'meio' de criação do bem-estar do homem, afinal, o trabalho é central na vida do homem, diferenciando-o dos animais justamente por sua capacidade criadora de gerar meios para superar suas necessidades e garantir uma vida melhor.

A proposta de integração curricular é nesse sentido, uma estratégia para uma educação diferenciada, que mesmo estando 
no viés do Estado, abre-se uma possibilidade de, na contradição, construir uma perspectiva progressista, que vise o ser humano e não o mercado de trabalho.

O Currículo integrado faz parte de uma concepção de organização da aprendizagem que tem como finalidade oferecer uma educação que contemple todas as formas de conhecimento produzidas pela atividade humana. Trata-se de uma visão progressista de educação à medida que não separa o conhecimento acumulado pela humanidade na forma de conhecimento científico daquele adquirido pelos educandos no cotidiano das suas relações culturais e materiais. Por essa razão, possibilita uma abordagem da realidade como totalidade, permitindo um cenário favorável a que todos possam ampliar sua leitura sobre o mundo e refletir sobre ele para transformá-lo no que julgarem necessário. O ensino integrado tem por objetivo "disponibilizar aos jovens que vivem do trabalho a nova síntese entre o geral e o particular, entre o lógico e o histórico, entre a teoria e a prática, entre o conhecimento, o trabalho e a cultura" (KUENZER, 2002, p. 43-44).

Por se tratar da integração da formação básica com a formação profissional, o Currículo integrado possibilita que os trabalhadores tenham acesso aos bens científicos e culturais da humanidade ao mesmo tempo em que realizam sua formação técnica e profissional. Essa formação se diferencia dos projetos vinculados aos interesses de mercado, uma vez que é bem mais que isso. É um ensino que pretende formar um profissional crítico, que seja capaz de refletir sobre sua condição social e participar das lutas em favor dos interesses da coletividade.

Como formação humana, o que se busca é garantir ao adolescente, ao jovem e ao adulto trabalhador o direito a uma formação completa para a leitura do mundo e para a atuação como cidadão pertencente a um país, integrado dignamente à sua sociedade política. Formação que, neste sentido, supõe a compreensão das relações sociais subjacentes a todos os fenômenos. (CIAVATTA, 2005, p. 85)

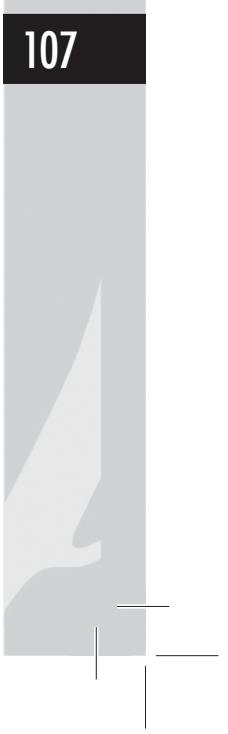




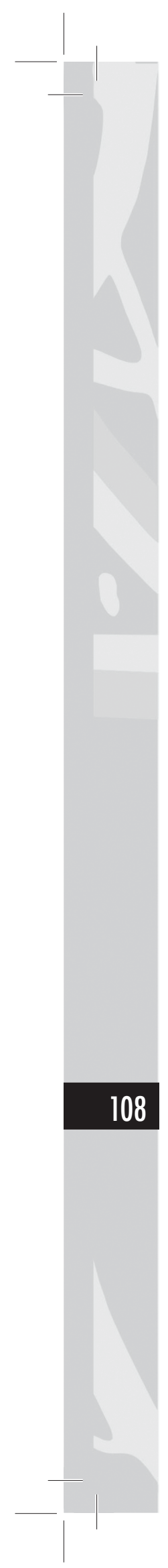

O currículo escolar, em uma sociedade de classes, constitui a representação dos interesses do pensamento dominante, mas também traz em si contradições que podem ser identificadas pelo princípio básico da dialética. O Currículo integrado é uma forma de organização do conhecimento escolar que permite a compreensão das relações complexas que compõem a realidade e possibilita a emancipação dos educandos. Seu caráter transformador está em romper com as fragmentações que dificultam o desvelamento das contradições presentes nessa sociedade.

A integração curricular, no entanto, não se realiza apenas pela oferta de disciplinas da educação profissional e da educação básica. Integrar requer uma leitura da realidade concreta, com a participação dos sujeitos envolvidos na aprendizagem, para desvelar suas relações e suas especificidades. Para isso, é necessário mais do que práticas de cooperação entre as disciplinas do conhecimento científico. "A integração exige que a relação entre conhecimentos gerais e específicos seja construída continuamente ao longo da formação, sob os eixos do trabalho, da ciência e da cultura" (RAMOS, 2005, p. 122). O exercício da aprendizagem, nessa perspectiva, tem relações estreitas com as condições específicas dos educandos e educadores. Por isso, integrar sob os eixos do trabalho, da ciência e da cultura como operação didática e pedagógica pressupõe um olhar comprometido com as relações estabelecidas no lugar da aprendizagem. Esse compromisso é político e, como tal, requer a compreensão de que educar exige interferir em determinada realidade e tomar posição. "Não posso ser professor se não percebo cada vez melhor que, por não poder ser neutra, minha prática exige de mim uma definição" (FREIRE, 2010, p. 102). O Currículo integrado, portanto, inscreve-se entre as propostas de educação, cujo objetivo é romper com a ideia de neutralidade e é favorável aos processos de ensino e aprendizagem que concorram para a emancipação dos trabalhadores. 


\section{ambiental \\ 2 Biodiversidade, currículo integrado e educação}

O Brasil concentra em seus limites a maior biodiversidade de organismos e de ecossistemas do globo. O país lidera o ranking da biodiversidade de plantas, peixes de água doce e mamíferos; ocupa a segunda posição na diversidade de anfíbios; a terceira em aves e a quinta em répteis. A floresta tropical úmida - que cobre cerca de $7 \%$ do planeta - contém, segundo estimativas, cerca de $50 \%$ da biodiversidade mundial. A Amazônia brasileira, com 7 milhões de $\mathrm{km} 2$, ocupa $80 \%$ da Amazônia sul-americana e representa um percentual de $67 \%$ das florestas tropicais do mundo.

Apesar das grandes potencialidades dessa megabiodiversidade, pode se dizer que o país ainda subaproveita essa riqueza biológica, tanto em termos econômicos como sociais. Grande parte dessa diversidade de espécies ainda não é conhecida por pesquisadores, e apenas uma pequena parcela de espécies descritas é utilizada de forma efetiva pela sociedade brasileira, em termos de benefícios sociais, econômicos, garantindo-se melhoria da qualidade de vida da população de modo geral. Observa-se que o retorno para o setor produtivo e para as comunidades ainda é muito aquém em relação ao potencial previsto por especialistas.

Essas questões adquirem um status preocupante dado que os mecanismos de proteção e conservação dos ecossistemas naturais, mantenedores dessa biodiversidade, ainda apresentam muitas imperfeições, o que tem refletido em um grande número de espécies e de biomas estar ameaçado e em processo de extinção, mesmo com o fortalecimento do movimento ambientalista nas últimas décadas e a ocorrência de uma evolução global da consciência ecológica. Se as políticas públicas voltadas para a conservação dos recursos naturais ainda são insatisfatórias, pode-se dizer que ainda mais embrionário é o estado da arte das políticas públicas relativas ao aproveitamento sustentável do imenso potencial socioeconômico da biodiversidade brasileira.

Sem dúvida, a utilização sustentável de componentes da biodiversidade constitui o novo desafio a encarar, condição

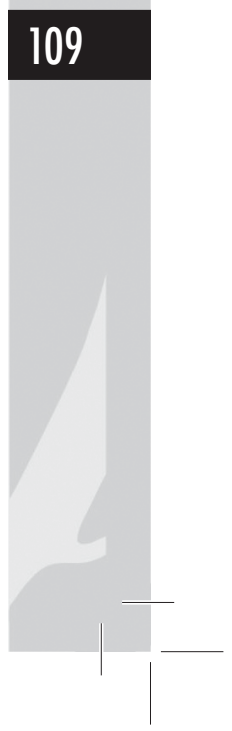




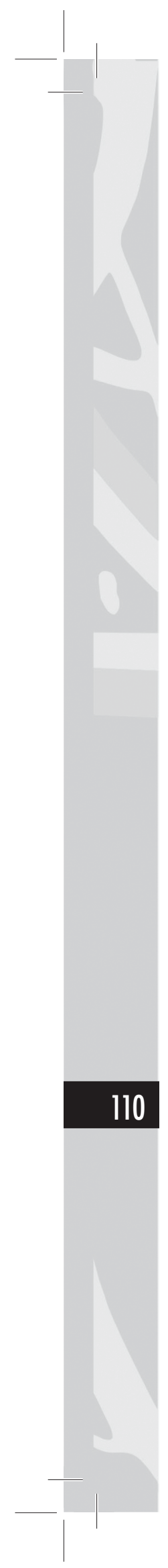

essencial para o progresso na apropriação dos meios de produção, atualmente limitados pela pequena variedade de espécies da floresta manejados e comercializados, o que vem colocando a chamada "economia da floresta em pé" ainda em condições de desvantagem em relação às práticas agrícolas e agroflorestais baseadas na substituição da floresta.

Duas dinâmicas econômicas em crescimento, cujos atores são, predominantemente, pequenos produtores, os sistemas extrativistas e a chamada colonização agrícola, necessitam urgentemente de novas alternativas de geração de renda a partir da floresta, de forma a valorizar cada vez mais a biodiversidade ainda presente, ao mesmo tempo em que possibilitem a recuperação econômica de grandes extensões de áreas degradadas, criadas a partir de tecnologias inadequadas às condições naturais existentes.

Tal desafio vem esbarrando no despreparo dessas organizações populares para tratar o tema da biodiversidade, cujas nuances envolvem princípios legais e padrões tecnológicos relativamente novos, cujo desenvolvimento e definições ainda não estão completos. Alguns temas, como o acesso ao conhecimento tradicional e a repartição de benefícios derivados, contêm indefinições legais com frentes de discussão ainda abertas no nível internacional.

Para inserir de forma plena essas comunidades no processo de apropriação dos componentes da biodiversidade, constituindo o controle social necessário para evitar a formação de novos enclaves econômicos na região, e garantir a repartição dos benefícios oriundos dessa nova dinâmica, faz-se necessário um amplo processo de capacitação desse segmento social, com base na resolução dos obstáculos à construção de novas cadeias produtivas, sob os aspectos legais, tecnológicos, institucionais e organizacionais. Tal processo precisa ser construído de forma participativa, quando as demandas sejam identificadas pelos próprios atores, com apoio dos especialistas nas diversas áreas a serem abordadas. Essa perspectiva, lida com um desafio: aproximar as discussões de interesse da biodiversidade e a educação. 
A Educação como eixo principal na formação de saberes, é um dos mais eficientes caminhos para a conservação das riquezas naturais, pois leva à construção da conscientização, seja ela individual ou coletiva, tratando da problemática ambiental e de suas consequências à vida humana, gerando o surgimento de novas atitudes. A Educação Ambiental (EA), como educação crítica e transformadora, coletiva, contínua, e de caráter interdisciplinar, pode impulsionar processos participativos que favoreçam a conservação de áreas de proteção ambiental e contribuir para o envolvimento das populações do entorno, refletindo em exercício de cidadania.

Barcelos (2002) entende que a expressão "Educação Ambiental" não pode ser entendida simplesmente como algo que se aproxime das boas práticas ambientais ou ainda de comportamentos ecologicamente corretos. Para Sato (2002), a Educação Ambiental é um processo que consiste em propiciar às pessoas uma compreensão crítica e global do ambiente, para assim poder elucidar valores e desenvolver atitudes que lhe permitam adotar uma posição consciente e participativa, com relação às questões voltadas a conservação.

A relação dos conhecimentos de biodiversidade e educação precisa está aplicada no currículo integrado, resultando, assim, em práticas de educação ambiental interdisciplinares. Ao ser considerada a Educação Ambiental como um processo social indispensável à formação da mentalidade dos cidadãos de uma sociedade, passa-se à crença de que a escola é o espaço ideal para a socialização do conhecimento que é o resultado de um longo processo: a relação do homem com a natureza e com os outros homens. A reconstrução do conhecimento no interior de uma escola é o currículo integrado, que também é um processo social cuja função é dar àquele que aprende acesso à história da humanidade e, ao mesmo tempo, proporcionarlhe conhecimento necessário à sua inserção como sujeito nessa mesma história.

A Educação Ambiental vem adquirindo uma grande importância no mundo, sendo hoje pertinente que os currículos escolares busquem desenvolver práticas pedagógicas 


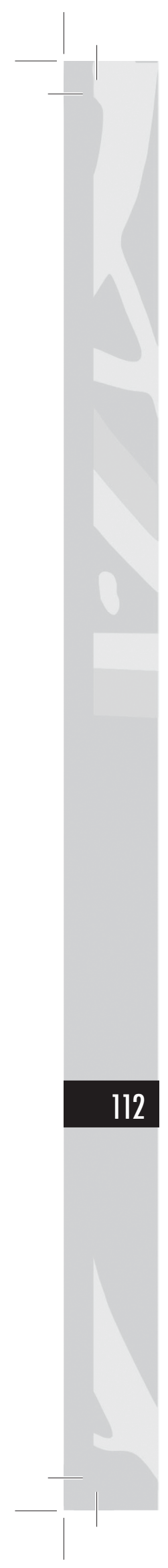

ambientalizadas. Assuntos como ética, estética, respeito e cidadania planetária devem estar presentes diariamente na rotina da sala de aula.

Como perspectiva educativa, a Educação Ambiental deve estar presente no currículo de todas as disciplinas, uma vez que permite a análise de temas que enfocam as relações entre a humanidade, o meio natural e as relações sociais, sem deixar de lado suas especificidades. Essa prática pedagógica precisa ser compreendida como um currículo integrado entre educação ambiental e conhecimentos da biodiversidade.

É necessário ter claro que a Educação Ambiental não deve estar presente no currículo escolar como uma disciplina, porque ela não se destina a isso, mas, sim, como um tema que permeia todas as relações e atividades escolares, buscando desenvolver-se de maneira interdisciplinar, conforme preconiza o Plano Nacional de Educação Ambiental - Lei 9795/99. Em praxe, a educação ambiental precisa ser uma ação pedagógica de currículo integrado, focando sua competência para a interdisciplinaridade.

A interdisciplinaridade é explicada por Norgaard (1998) através de uma metáfora muito interessante, nela ele simboliza a orquestra para explicar a importância da interdisciplinaridade. Se todos os pesquisadores envolvidos numa pesquisa tivessem os mesmos entendimentos sobre um determinado conhecimento, estaríamos tocando um só instrumento e alcançando as mesmas notas musicais. Mas ter conhecimentos complementares ou divergentes seria comparável a uma orquestra, na qual tocar juntos requer uma partitura mais elaborada e uma competência mais considerável. Ainda que numa orquestra os músicos não possam escolher as partituras que tocam juntos ou eleger o regente, o som da improvisação orquestral pode representar uma revolução, em que a dissonância pode ser compreendida como parte da transição da modernidade, e na qual os conhecimentos se complementam para a interpretação conjunta de uma realidade.

Portanto, a dimensão ambiental traz a necessidade de uma rica orquestra musical, uma vez que a educação ambiental deve ser entendida como educação política, no sentido de que 
ela reivindica e prepara os cidadãos para exigir justiça social, cidadania nacional e planetária, autogestão e ética nas relações sociais e com a natureza, e para tanto precisa que o currículo seja integrado, de interdisciplinar aos conhecimentos de biodiversidade amazônica, em especial.

Para Moreira, "nas escolas não se aprendem apenas conteúdos sobre o mundo natural e social; adquirem-se também consciência, disposições e sensibilidades que comandam relações e comportamentos sociais do sujeito e estrutura sua personalidade" (1995, p. 50). Assim, a interdisciplinaridade envolve muito mais do que integração entre as disciplinas, ela precisa envolver conhecimentos do cotidiano dos alunos e que lhes traga significado. Por isso, a Educação Ambiental precisa fazer parte do cotidiano escolar, para refletir sobre questões atuais e pensar em que mundo se deseja viver, e, então, pôr em prática a máxima do pensamento ecologista mundial de poder agir local e pensar global.

A maneira como o currículo é oferecido na maioria das escolas não permite um arranjo flexível para que os professores possam incluir a dimensão ambiental em suas aulas. É necessário que o currículo seja entendido como "algo que se constitui nas relações intersubjetivas na comunidade escolar, relações essas inerentemente políticas, e, portanto, mesmo que implicitamente sempre intencionais. Currículo é um processo inacabado" (GALIAZZI, GARCIA et al. 2002, p. 100). É concordando com Sacristán (1998), que compreende o currículo como algo construído no cruzamento de influências e campos de atividades diferenciadas e inter-relacionadas, permitindo analisar o curso de objetivação e concretização do currículo em vários níveis e assinalando suas múltiplas transformações, que se viabiliza a Educação Ambiental na escola. Essa visão de Sacristán é clara na percepção de currículo integrado.

De acordo com Sato,

Há diferentes formas de incluir a temática ambiental nos currículos escolares, como atividades artísticas, experiências práticas, atividades fora da sala de aula,

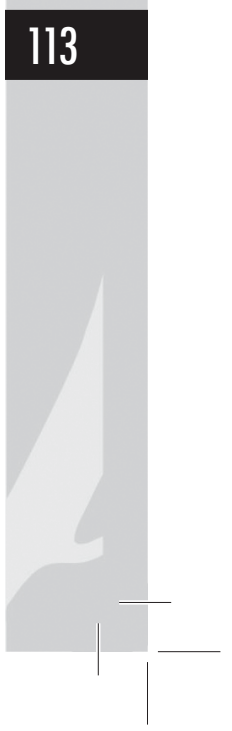




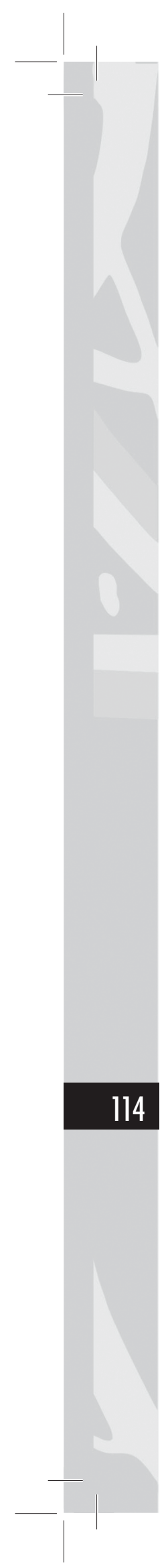

produção de materiais locais, projetos ou qualquer outra atividade que conduza os alunos a serem reconhecidos como agentes ativos no processo que norteia a política ambientalista. Cabe aos professores, por intermédio de prática interdisciplinar, proporem novas metodologias que favoreçam a implementação da Educação Ambiental, sempre considerando o ambiente imediato, relacionado a exemplos de problemas atualizados. (2003, p. 25)

Atualmente, o currículo escolar vem transformando-se e atendendo as exigências do paradigma da pós-modernidade, que entende a sociedade como uma totalidade. Segundo Santos (2000), a modernidade está assentada sobre dois pilares de construção do conhecimento, no qual o primeiro é o conhecimento-regulação e o segundo o conhecimentoemancipação. Considerando que o conhecimento que se consagrou foi o conhecimento regulação, dominando e anulando as possibilidades de implementação do conhecimento emancipação.

Conforme Barcelos (2002), a retomada do conhecimentoemancipação permitirá o surgimento de uma nova relação entre conhecimento e cidadania, em que o ato de conhecer é também ato de reconhecer que o outro não mais é visto tomado apenas como objeto, mas como sujeito do conhecimento. E é para esse tipo de conhecimento que a Educação Ambiental está voltada, um conhecimento construído, desenvolvimento da cidadania, da autonomia e da ética.

Entretanto, Barcelos (2002) aponta que, para se atingir o conhecimento da emancipação é necessária uma construção paradigmática, que "permite distinguir as disciplinas sem, no entanto, separá-las, isolá-las, associar, sem, com isso, reduzir ou anular qualquer uma das partes ou disciplinas envolvidas". $\mathrm{O}$ que não será uma tarefa muito fácil, tendo em vista que tudo no mundo está fragmentado, mas para se construir uma conscientização ambiental/planetária é necessário desconstruir a compartimentalização do conhecimento. 
Considerando que a Educação Ambiental tem por objetivo a busca do conhecimento integrado de todas as áreas para a solução dos problemas ambientais, a fragmentação do conhecimento perde o sentido, uma vez que esta educação visa o conhecimento emancipação. Portanto, a Educação Ambiental tem sido identificada como transdisciplinar, isso é, transpassa todas as disciplinas já que ela, segundo Sato, "sustenta todas as atividades e impulsiona os aspectos físicos, biológicos, sociais e culturais dos seres humanos" (2002, p. 24), e para se efetivar, nesse paradigma pedagógico, é necessário que o currículo, além de interdisciplinar, precisa ser integrado aos conhecimentos e atitudes de biodiversidade, com foco na Amazônia.

Porém, a construção de um currículo deve levar em conta o indivíduo, sua sociedade e sua história de forma a criar uma situação de um compromisso que possa gerar a transformação. Sobre o desenvolvimento de um currículo, Giesta, assim se pronuncia:

O estudante analise a coerência de seus próprios valores e comportamentos, assim como da sociedade; aprenda a obter informações e desenvolver competências para perceber o ambiente particular como parte da sociedade global, entre outras aprendizagens que lhe dêem suporte para melhor compreender o mundo, os fatos, as pessoas. (1999, 120p).

Portanto, é evidente a necessidade de trazer para os currículos escolares os conhecimentos, os valores e comportamentos do estudante e da sociedade da qual ele é partícipe em uma relação recíproca de influências que envolvem uma variedade de conceitos e visões de mundo. As palavras de Giesta expressam essa realidade da seguinte maneira: "a educação se dá na interação com as pessoas e com o meio ambiente" (1994, p. 183).

Percebe-se, então, que o currículo é uma construção social, no sentido que está diretamente ligado a um momento histórico, a uma determinada sociedade e as relações que essa estabelece com o conhecimento. Partindo disso, existe nas 
diversas realidades uma pluralidade de objetivos com relação ao que ensinar, no sentido de que os conteúdos propostos compõem um quadro bastante diverso e ao mesmo tempo peculiar.

Desse modo, a escola ao propor o desenvolvimento do currículo escolar voltado para a questão ambiental, deve proporcionar a participação de todos no processo de sua construção, execução, tendo os alunos como sujeitos do processo, ou seja, propor um currículo integrado. Os conteúdos precisam ser revistos para que os mesmos convirjam entre as disciplinas de forma interdisciplinar, além de terem sua importância na Educação Ambiental.

\section{REFERÊNCIAS}

BARCELOS, T. M. (2002). Subjetividade: inquietações contemporâneas. Educação e filosofia, v. 32, n. 16, p. 149-159.

BERNSTEIN, Basil. A estruturação do discurso pedagógico: classe, códigos e controle. Petrópolis: Vozes, 1996a.

Pedagogia, control simbólico e identidad: teoria, investigación crítica. Madri: Morata, 1996b.

CIAVATTA, Maria. A formação integrada: a escola e o trabalho como lugares de memória e de identidade. In: FRIGOTTO, Gaudêncio; CIAVATTA, Maria; RAMOS, Marise. (orgs.). Ensino médio integrado: concepção e contradições. São Paulo: Cortez, 2005.

DAVINI, Maria Cristina. Currículo integrado. 2009. Disponível em: $<$ http://www.opas.org.br/rh/publicacoes/textos_apoio/pub04U2T8. pdf>. Acesso em: 20 set. 2013.

FREIRE, Paulo. Pedagogia da autonomia. São Paulo: Paz e Terra, 2010. 
GALIAZZI, M. C. et. al. Construindo Caleidoscópios: organizando unidades de aprendizagem. Revista eletrônica do Mestrado de Educação Ambiental, Rio Grande, v. 9, p. 98-111, jul.- dez. 2002.

GIESTA, N.C. Tomada de decisões pedagógicas no cotidiano escolar. Porto Alegre: UFRGS, 1994.

KUENZER, Acácia Zeneida. (org.). Ensino médio: construindo uma proposta para os que vivem do trabalho. 3. ed. São Paulo: Cortez, 2002.

Exclusão includente e inclusão excludente: a nova forma de dualidade estrutural que objetiva as novas relações entre educação e trabalho. 2003. Disponível em: <http://forumeja.org.br/ go/files/13\%20Exclusao\%20Includente\%20Acacia\%20Kuenzer_1. pd >. Acesso em: 22 jun. 2011.

MEC/SEMTEC. Parâmetros Curriculares Nacionais. Brasília, $1999,1,2,3,4 \mathrm{v}$.

MOREIRA, A. F. Currículos e programas no Brasil. Campinas: Papirus, 1995.

MOREIRA, A. F. e SILVA, T. T. (orgs.) Currículo, cultura e sociedade. 4. ed. São Paulo: Cortez, 2000.

NORGAARD, Richard. A improvisação do conhecimento discordante. Ambiente \& Sociedade, ano I, n. 2, p. 25-40, 1998.

RAMOS, Marise. Possibilidades e desafios na organização do currículo integrado. In: FRIGOTTO; Gaudêncio; CIAVATTA, Maria; RAMOS, Marise. (orgs.). Ensino médio integrado: concepções e contradições. São Paulo: Cortez, 2005.

SACRISTÁN, J. G. O currículo: uma reflexão sob a prática. 3. ed. Porto Alegre: Artes Médicas, 1998. 
SACRISTÁN, J. G. e GOMES, A. I. P. Compreender e transformar o ensino. 4. ed. Porto Alegre: Artmed, 1998.

SACRISTÁN, J. G. O currículo: uma reflexão sob a prática. 3. ed. Porto Alegre: Artmed, 1998.

SANTOS, B. S. A crítica da razão indolente - contra o desperdício da experiência. São Paulo: Cortez, 2000.

SATO, M. Educação Ambiental. São Carlos: Rima, 2002.

SILVA, T. T. da. Documentos de identidade: uma introdução às teorias do currículo. Belo Horizonte: Autêntica, 1999.

O currículo como fetiche: a poética e a política do texto curricular. 2. ed. Belo Horizonte: Autêntica, 2001. 